\title{
Trabalhonecessário
}

Issn: 1808 - 799X

ano 12, no $18-2014$

Documentos e Memórias

\section{EDUCAÇÃO - REFORMA DE BASE: CINQUENTENÁRIO DE UMA PROPOSTA GOLPEADA}

\author{
Francisco José da Silveira Lobo Neto ${ }^{1}$
}

\section{Introdução}

Dois dias após o Comício da Central (13 de março de 1964), o Presidente João Goulart enviou Mensagem ao Congresso Nacional, conclamando parlamentares e lideranças a realizar as Reformas de Base. Quinze dias depois, um golpe civil e militar depôs o Presidente.

Desde 1961, quando houve a renúncia do Presidente Janio Quadros e a posse de Goulart no contexto do compromisso parlamentarista, setores conservadores da sociedade brasileira acompanhavam as ações de governo com desconfiança e conspiração. Os acontecimentos daqueles dias parecem indicar a presença de "ilhas de conspiração" tão desarticuladas, quanto desarticuladas estavam as forças de apoio ao governo. E parece certo que esta desarticulação golpista manifesta-se com a precipitação do General Mourão movimentando suas tropas de Minas Gerais em direção ao Rio de Janeiro na madrugada de 31 de março.

\footnotetext{
1 Mestre e doutor em Educação. Professor-Pesquisador colaborador do Programa de Pósgraduação em Educação Profissional em Saúde da EPSJV/FIOCRUZ. sloboneto@gmail.com
} 


\section{Trabalhonecessário}

Issn: 1808 - 799X

ano 12 , no $18-2014$

A desintegração do esquema de segurança do Presidente da República fica patente com seu vôo do Rio de Janeiro para Brasília, depois para o Rio Grande do Sul, tentando resistir.

O Senador Auro de Moura Andrade declara vago o cargo de Presidente da República dando posse ao Deputado Ranieri Mazzilli, Presidente da Câmara dos Deputados, no dia 02 de abril. Na mesma data, o brigadeiro Francisco de Assis Correia de Melo (Aeronáutica), o vice-almirante Augusto Rademaker (Marinha) e o general Artur da Costa e Silva (Exército), se proclamam membros do "Comando Supremo da Revolução". Em 09 de abril, investindo-se do Poder Constituinte, editam o Ato Institucional n. 1, marcando para o dia 11 de abril a eleição de Presidente e Vice-Presidente da República, a serem empossados em 15 de abril.

Passados cinqüenta anos, trazemos à memória de nossos leitores as propostas de reforma educacional, tal como expressas na Mensagem Presidencial ao Congresso, datada de 15 de março de 1964 e os primeiros atos do autodenominado "governo revolucionário".

\section{Contexto da reforma educacional de base}

Dois dias antes de enviar a Mensagem, no discurso do já mencionado Comício da Central, João Goulart informou: "Dentro de 48 horas, vou entregar à consideração do Congresso Nacional a mensagem presidencial deste ano. Nela, estão claramente expressas as intenções e os objetivos deste governo. Espero que os senhores congressistas, em seu patriotismo, compreendam o sentido social da ação governamental, que tem por finalidade acelerar o progresso deste país e assegurar aos brasileiros melhores condições de vida e trabalho, pelo caminho da paz e do entendimento, isto é pelo caminho reformista". E prosseguiu: "Também está consignada na mensagem ao Congresso a reforma universitária, reclamada pelos estudantes brasileiros. Pelos universitários, classe que sempre tem estado corajosamente na vanguarda de todos os movimentos populares nacionalistas". 


\section{Trabalhonecessário}

Issn: 1808 - 799X

ano 12, no $18-2014$

A Mensagem ao Congresso Nacional e seus anexos vai bem mais longe, cobrindo todos os níveis e modalidades de educação, como se pode apreender no Documento 1. Iniciada com uma ampla análise do momento vivido pela sociedade brasileira, - caracterizado pela consciência das "condições de atraso", pela inconformidade "com a ignorância e a miséria", pela deliberação em progredir - a Mensagem propõe a superação desse contexto com "reformas capazes de substituir as estruturas existentes por outras compatíveis com o progresso realizado e com a conquista dos novos níveis de desenvolvimento e bem estar" (p. VI).

O Presidente reconhece "como encargo primeiro e responsabilidade mais alta da investidura com que me honrou a vontade dos meus concidadãos... 0 comando da luta pela renovação pacífica da sociedade brasileira". E o faz através da iniciativa de combater os privilégios e de propor "as reformas de base" para a "substituição de estruturas e instituições inadequadas à tranquila continuidade do nosso progresso e à instauração de uma convivência democrática plena e efetiva" (p. VI-VII).

Mesmo antes das medidas legais necessárias à "implantação das reformas estruturais com a profundidade que a Nação exige", ressalta os esforços do governo em ações para "satisfação dos reclamos populares e na defesa dos interesses do País" (p. XI).

Especificamente sobre a educação, explicita o "propósito de integrar na comunidade brasileira largas faixas marginais da nossa população" e registra as providências tomadas pelo Poder Executivo desencadeando "um movimento, hoje irreversível, no sentido da democratização do ensino e da adequação de nosso sistema educacional às exigências do desenvolvimento do País" (p. XXI). Entre outras iniciativas menciona:

a) atribuir "aos Estados e aos Municípios somas sempre maiores de recursos para que se possa proporcionar o ensino primário, de 4 anos, a toda a população em idade escolar" (ibidem); 


\section{Trabalhonecessário}

Issn: 1808 - 799X

ano 12, no $18-2014$

b) promover "programa de construção de 5.800 salas de aula e reequipamento de mais de 10.000 e de suplementação dos salários da professora primária", com o objetivo de "assegurar, este ano [1964], um incremento de mais de dois milhões de vagas, em nossa rede de escolas primárias" (ibidem);

c) desenvolver de "campanha de alfabetização de adultos... para a erradicação do analfabetismo", de grande amplitude e contando com a participação de professores, estudantes, e de "todas as pessoas, entidades e instituições que possam contribuir com uma parcela de seu esforço" (p.XXII);

d) executar, por meio do Ministério da Educação, o "programa para a democratização da escola de grau médio e sua adaptação às necessidades de habilitação da juventude para as tarefas do desenvolvimento" tem como objetivo "possibilitar a instalação, em todos os municípios brasileiros, de escolas de ensino de grau médio, voltadas todas no sentido da educação para o trabalho" (ibidem);

e) reformular os "currículos universitários" e duplicar as "matrículas no primeiro ano dos cursos de nível superior", considerados "primeiros passos para, efetivamente, integrar a Universidade no processo nacional de emancipação econômica e cultural", ao mesmo tempo em que se abrem "mais largamente as portas ao maior número de jovens aptos a receber preparo científico e treinamento técnico moderno" (ibidem).

\section{Início do "golpe na educação"}

Pouco mais de sessenta dias de sua posse como Presidente da República no Governo Ditatorial de Exceção, o General Humberto de Alencar Castelo Branco faz uma radical releitura da reforma educacional necessária ao País, em seu discurso na Universidade Federal do Ceará, em 23 de junho de 1964.

Desde o seu início, denuncia omissões e, sobretudo ações condenáveis no campo educacional. Textualmente: "É do conhecimento de todos a grave e lamentável situação que a Revolução encontrou no setor da educação, onde o poder público não pecou apenas pela omissão, mas também pela complacência 


\section{Trabalhonecessário}

Issn: 1808 - 799X

ano 12, no $18-2014$

e, por vezes, pela ação deletéria. Era com a própria orientação, com o apoio ostensivo e, mais do que isso, com a ajuda perdulária do Ministério da Educação e Cultura, que se desenvolvia uma obra de agitação e subversão" (p. 134).

$E$, no que se refere ao ensino superior e às Universidades, o General-

Presidente é taxativo em sua crítica ao passado próximo: "Muito se tem falado, nos últimos tempos, em reforma universitária. Contudo, nem sempre os propósitos têm sido os alardeados, que apenas escondem a criação de um clima de agitação incompatível com os melhores objetivos. Aliás, entre as metas educacionais do Governo está a revisão da estrutura universitária, a começar pelo estatuto do Magistério. Uma sucessão de federalizações sobrecarregou o Erário Público, impedindo-o de atender alguns setores onde se faz reclamada a sua assistência. Em Estados que estão longe de haver solucionado os problemas de ensino primário e médio, vemos Universidades bastante dispendiosas. Assim, somente quando provada a imperiosa necessidade, autorizará o Governo a criação de escolas superiores. Insistirá, principalmente, na orientação da Lei de Diretrizes e Bases, que preconiza a formação de fundações e autarquias para atender ao ensino superior, do mesmo modo que exigirá dos cursos oficiais superiores, sem prejuízo da sua eficiência, admissão de número maior de jovens, a fim de vermos diminuído o alto custo de cada estudante superior anualmente" (p. $136-137)$.

Citando uma frase isolada de Amoroso Lima contra a "perigosa tendência de infiltrar a Universidade de preocupações políticas, especialmente entre o corpo discente, que poderá ser amanhã completamente desastrosa", o generalpresidente explicita que "a ação do Governo deverá estender-se à comunidade estudantil. Não se contesta aos moços das escolas superiores que se adestram para assumir, em breve, postos de atuação e orientação, o direito, e, mais do que o direito, o dever de tomarem conhecimento dos problemas nacionais. É mesmo recomendável que a mocidade sinta e viva esses problemas, no momento em que se apresentam e desenvolvem. É uma tomada de consciência que há de ser feita 


\section{Trabalhonecessário}

Issn: 1808 - 799X

ano 12, no $18-2014$

pelos moços no campo da aprendizagem e nos termos adequados à sua condição de cidadãos em fase de formação".

De fato, o primeiro Projeto de Lei do governo ditatorial sobre a educação nacional, foi o que "dispõe sobre os órgãos de representação dos estudantes e dá outras providências", aprovado e sancionado como a Lei n. 4.464 de 9 de novembro de 1964, também conhecida como a Lei Suplicy (Ministro da Educação). Esta Lei, disciplinando e limitando o movimento estudantil, é reproduzida abaixo como o Documento 2.

\section{Documentos:}

Trechos referentes à Educação na Mensagem do Presidente João Goulart ao Congresso Nacional, em 15 de março de 1964, e em seu Anexo.

Da Mensagem Presidencial

Realizações do governo

\section{Educação}

"Orgulha-se este Governo, Senhores Congressistas, de haver desencadeado, com o propósito de integrar na comunidade brasileira largas faixas marginais da nossa população, um movimento, hoje irreversível, no sentido da democratização do ensino e da adequação de nosso sistema educacional 'às exigências do desenvolvimento do Pais. Impressiona saber que somente $46 \%$ 'das crianças brasileiras freqüentam escolas e que menos de dois milhões de adolescentes, ou seja, apenas $10 \%$ dos maiores de 12 anos, conseguem ingressar nas escolas de grau médio.

A ação do Governo, para a mudança desse quadro aviltante, exercesse, fundamentalmente, para efeito de tornar o ensino primário efetivamente 


\section{Trabalhonecessário}

Issn: 1808 - 799X

ano 12, no $18-2014$

obrigatório e universal e abrir a um número sempre crescente de jovens o acesso à escola média, que deve transformar-se em centro de educação para o trabalho. Com tal propósito, vem a União atribuindo aos Estados e aos Municípios somas sempre maiores de recursos para que se possa proporcionar o ensino primário, de 4 anos, a toda a população em idade escolar. Por intermédio de convênios com os Estados e os Municípios.

O Ministério da Educação está executando um programa de construção de 5.800 salas de aula e reequipamento de mais de 10.000 e de suplementação dos salários da professora primária. Espera o Governo, com essas e outras providências, assegurar, este ano, um incremento de mais de dois milhões de vagas, em nossa rede de escolas primárias.

Simultaneamente, promove-se com amplitude jamais atingida, intensa campanha de alfabetização de adultos, à qual estão sendo convocados professores, estudantes, todas as pessoas, entidades e instituições que possam contribuir com uma parcela de. seu esforço, para a erradicação do analfabetismo. Extenso programa para a democratização da escola de grau médio e sua adaptação às necessidades de habilitação da juventude para as tarefas do desenvolvimento, foi elaborado pelo Ministério da Educação e encontra-se em fase executiva. Seu objetivo inicial é possibilitar a instalação, em todos os municípios brasileiros, de escolas de ensino de grau médio, voltadas todas no sentido da educação para o trabalho.

Quanto ao ensino superior, o esforço governamental destina-se a transformá-lo, efetivamente, em meio para a formação de técnicos de alto nível e que atendam às necessidades do progresso industrial. Mediante reformulação dos currículos universitários e pela duplicação de matrículas no primeiro ano dos cursos de nível superior, estamos dando os primeiros passos para, efetivamente, integrar a Universidade no processo nacional de emancipação econômica e cultural e para abrir-Ihe mais largamente as portas ao maior número de jovens aptos a receber preparo científico e treinamento técnico moderno. É justo pôr em relevo o papel pioneiro da Universidade de Brasília, novo modelo de universidade, 


\section{Trabalhonecessário}

Issn: 1808 - 799X

ano 12, no $18-2014$

inspirado, não só na experiência das mais avançadas organizações mundiais de ensino superior, como também nos reclamos da sociedade brasileira nessa fase decisiva de transformação sócio-cultural" (p. XXI-XXII).

\section{Planejamento como Norma de Governo}

Preocupou-se também a Administração em imprimir seq ência à atividade $p$ blica, com o que foi obtido melhor aproveitamento dos recursos disponíveis. Esse pensamento é que levou o Governo, em seguida à aprovação do Plano de Desenvolvimento Econômico e Social, à criação de um sistema de planejamento, com estrutura adequada à ordem institucional vigente, o que fez por intermédio do Decreto n 5 . 56, de 11 de julho de 1963, que criou a Coordenação do Planejamento Nacional. Existe, agora, um órgão aparelhado para orientar as providências governamentais e estabelecer os critérios que devem ser observados na execução de projetos prioritários, possibilitando, assim, correto desdobramento do Plano de Desenvolvimento" (p. XXXI-XXXII).

\section{Retomada de propostas de 1963}

"Senhores Membros do Congresso Nacional: meu Governo esteve sempre empenhado em obter a colaboração do Poder Legislativo, quer para a reestruturação institucional que há de permitir as transformações necessárias à continuidade do nosso desenvolvimento econômico e social , quer para o encaminhamento de questões específicas que atendam os justos reclamos populares.

À sábia apreciação de ossas Excelências apresentei, durante a sessão legislativa de 1963, uma série de proposições para as quais me permito, uma vez mais, solicitar a patriótica atenção da Câmara e do Senado" (p. XXXVIII).

[a Mensagem passa a explicitar as propostas anteriores: Reforma bancária, Sonegação fiscal, Reforma administrativa, Códigos, Salários móveis] 


\section{Trabalhonecessário}

Issn: 1808 - 799X

ano 12, no $18-2014$

"De ossas Excelências, Senhores Deputados e Senadores, espero, e, mais do que eu, espera o povo, a concretização dessas e de outras medidas que tenho proposto e virei ainda a propor ao Congresso Nacional com a exclusiva preocupação de assegurar a marcha ininterrupta deste País no sentido de sua completa emancipação econômica e de permitir às nossas populações os civilizados níveis de vida a que têm o direito de aspirar" ( $p . \mathrm{XL})$.

\section{As Reformas de Base}

"Sabem os nobres congressistas do empenho com que meu Governo se tem devotado à procura de uma solução harmônica e pacífica para o problema da renovação institucional de nossa Pátria. Logo depois de restaurado o regime presidencialista, por meio de um plebiscito histórico em cuja campanha as Reformas de ase constituíram o meu compromisso fundamental, entrei em entendimento com todas as forças políticas da Nação, num esforço ingente por encontrar a fórmula mais adequada para a sua consecução democrática" (p. L). $[\ldots]$

"No cumprimento desta missão de paz é que coloco diante dos nobres representantes do povo, para a sua alta apreciação, o corpo de princípios que se me afiguram como o caminho brasileiro do desenvolvimento pacífico e da maturidade da nossa democracia. aço-o com inteira consciência de minhas responsabilidades e para que jamais se diga que o Presidente da Rep blica não definiu com suficiente clareza o seu pensamento e a sua interpretação dos anseios nacionais, deixando de contribuir, por sua omissão, para o equacionamento e a solução do grande problema nacional do nosso tempo" ( $p$. LI). [explicita as Reformas Agrária e Política - p. LI-LVI e prossegue com a Reforma Universitária] 


\section{Trabalhonecessário}

Issn: 1808 - 799X

ano 12, no $18-2014$

Senhores Membros do Congresso Nacional:

É também imperativa a reforma dos dispositivos constitucionais, disciplinadores da educação nacional, a fim de ampliarem-se as garantias da liberdade do docente e redefinir-se $o$ instituto da cátedra, retirando-Ihe o caráter de domínio arbitrário e irresponsável de um campo do saber, para possibilitar ao ensino superior a renovação de seus quadros, o domínio da ciência e da técnica e maior eficácia na transmissão do conhecimento.

Para esse efeito, sugiro seja estudada pelo Congresso Nacional a conveniência de integrar no texto constitucional os seguintes princípios:

- assegurada ao professor de qualquer dos níveis de ensino plena liberdade docente no exercício do magistério.

- abolida a vitaliciedade da cátedra, assegurada aos seus titulares a estabilidade, na forma da lei.

- A lei ordinária regulamentará a carreira do magistério, estabelecendo os processos de seleção e provimento do pessoal docente de todas as categorias e organizará a docência, subordinando os professores aos respectivos departamentos.

- Às Universidades, no exercício de sua autonomia, caberá regulamentar os processos de seleção, provimento e acesso do seu pessoal docente, bem como o sistema departamental, 'ad referendum' do Conselho ederal de Educação" (p. LVI-LVII).

\section{Apelo final}

Senhores Membros do Congresso Nacional:

Atribuo a mais alta importância, para os destinos da nossa Pátria, à alteração dos textos constitucionais, à luz deste corpo de sugestões. Permitamme os nobres Congressistas assinalar que, a meu juízo, esses princípios, 


\section{Trabalhonecessário}

Issn: 1808 - 799X

ano $12, n^{\circ} 18-2014$

traduzidos em atos, contribuirão decisivamente para libertar as energias nacionais juguladas pela estreiteza de uma estrutura econômica inatual, cuja perpetuação somente serve a grupos privilegiados e já é incapaz de abrir perspectivas de progresso a uma Nação de 80 milhões de habitantes, que cresce num ritmo acelerado. Tais preceitos, se acolhidos pelo Congresso Nacional na reformulação de nossa Carta Magna, haverão de emancipar ó povo brasileiro das petas institucionais que o aviltam, pois o mantêm dividido em dois grupos que se extremam pelo contraste: um, o reduzido n cleo dos privilegiados; outro, a imensa massa dos deserdados dos quais tudo se exige, sem assegurar-Ihes sequer 0 calor da certeza de um futuro melhor.

, pois, com o mais alto apreço que me dirijo ao Congresso Nacional a fim de pedir-Ihe o exame desapaixonado das diretrizes aqui formuladas para as modificações do texto constitucional, visando à consecução pacífica e democrática das Reformas de ase.

Estou certo de que os nobres Parlamentares do rasil deste ano de 1964, guardam fidelidade às honrosas tradições dos nossos antepassados, que, em conjunturas semelhantes da vida nacional, como a Independência, a Abolição da Escravatura, a Proclamação da Rep blica e a Promulgação da Legislação Trabalhista, tiveram a sabedoria e a grandeza de renovar instituições básicas da Nação, que se haviam tornado obsoletas, assim salvaguardando 0 desenvolvimento pacífico do povo brasileiro.

O desafio histórico repete-se outra vez. Agora, nossa geração é que está convocada para cumprir a alta missão de ampliar as estruturas sócio-econômicas e renovar as instituições jurídicas, a fim de preservar a paz da família brasileira e abrir à Nação novas perspectivas de progresso e de integração de milhões de patrícios nossos numa vida mais compatível com a dignidade humana.

rasília, 15 de Marco de 1964. João Goulart”. (p. LIX-LX).

Do Anexo da Mensagem Presidencial (ações e intenções do Governo) 


\section{Trabalhonecessário}

Issn: 1808 - 799X

ano 12 , no $18-2014$

\section{PROGRESSO SOCIAL}

\section{Desenvolvimento Cultural}

\section{Educação}

\section{on ide aç e e ai}

m governo voltado para as legítimas reivindicações populares - neste momento em que vastas áreas das populações marginais do País aspiram à integração na vida social e política c à redenção econômica — não poderia deixar de estar atento ao problema da educação nacional. Pois nele se encontra instrumento insubstituível para as soluções reclamadas pelo tipo de sociedade que o povo brasileiro está construindo.

Neste País em que amplas camadas populares já foram atingidas, decisivamente, pelas mudanças dos métodos de produção e no qual se altera, rapidamente, o teor das relações sociais, a democratização do ensino é condição básica para a continuidade do desenvolvimento econômico e o próprio funcionamento do regime democrático. Sem sistema escolar que assegure educação às gerações jovens, a participação no processo político e o domínio das modernas técnicas de produção ficariam restritos à minoria privilegiada que pode freq entar as escolas dos diversos graus.

Os fenômenos da industrialização e da urbanização - normais em regime de desenvolvimento - exigem urgentes medidas de habilitação profissional, já para as populações rurais, que têm o encargo do abastecimento, já para as populações urbanas, já pa-ra os que emigram para as cidades, atraídos pelas novas oportunidades de emprego que o surto industrial oferece. A verdade é que há, presentemente, um profundo desajustamento cultural de massas consideráveis de nossas populações em face das mudanças estruturais provocadas pelo crescimento econômico do País. Os campos despovoam-se, porque não se procede a rápida mudança de processos agrícolas e das relações de trabalho, enquanto as cidades ficam sitiadas por populações adventícias que 


\section{Trabalhonecessário}

Issn: 1808 - 799X

ano 12, no $18-2014$

acorreram ao chamado da industrialização, mas não conseguiram a necessária integração ao meio urbano, com suas formas de vida cada vez mais dependentes de complexos processos tecnológicos. Não mais se pode esperar, assim, que as próprias forças sociais espontâneas corrijam, ainda que lentamente, os danos provocados pelas mudanças estruturais. $\mathrm{Na}$ conjuntura atual, cabe ao poder $\mathrm{p}$ blico tomar providências para que o desenvolvimento não se faça a preço tão oneroso e com tanto sacrifício das populações menos favorecidas.

A incapacidade do nosso sistema educacional para atender às solicitações do desenvolvimento e do processo de democratização da sociedade brasileira, há muito evidente, obrigou este Governo a um esforço extraordinário de revisão de objetivos, fundamentos e métodos da política nacional de educação.

Se tradicionalmente, a amplitude e a qualidade dos sistemas escolares eram consideradas simples conseq ência de firme e próspera economia, acredita-se, hoje, que a educação é uma das condições mesmas do desenvolvimento, na medida em que promove a habilitação de populações para melhorar, em bases tecnológicas, os índices de produção e propiciar a elevação dos níveis das aspirações populares.

Daí a legitimidade da ambição, formulada por este Governo, de pôr o sistema educacional brasileiro, não somente em consonância com as necessidades presentes do País, mas, ainda, de lhe imprimir características científicas das mais avançadas.

A complexidade progressiva da civilização, caracterizada pelo avanço da tecnologia, levou os estudiosos da educação a reconhecer que um sistema escolar capaz, apenas, de atender a primeira fase de maturação do ser humano é de todo em todo insuficiente, razão por que vem crescendo o período de escolaridade da juventude nos países mais adiantados. Os educadores reconhecem, igualmente, que educação é fenômeno contínuo e continuado, independentemente da idade dos indivíduos e do seu grau de cultura. Pois não é só a mudança tecnológica que exige a permanente revisão da habilitação técnica dos indivíduos, mas, por igual, a extensão e o aprofundamento do regime 


\section{Trabalhonecessário}

Issn: 1808 - 799X

ano 12, no $18-2014$

democrático, que coloca o povo diante de complexos problemas para a solução dos quais deve estar .em condições de contribuir conscientemente.

Compreendeu-se, finalmente, que os textos constitucionais e as leis protetoras dos economicamente mais fracos nenhum efeito possuem se eles não forem preparados, culturalmente, para; o exercício pleno de seus direitos e para o correto desempenho de seus deveres. Sem tal condição, os direitos constitucionais são apenas letra morta, e in til será esperar que todos possam oferecer, para o progresso político e social, a contribuição que seria lícito deles exigir.

erifica-se, ainda, que num país como o rasil, onde permanecem profundos desequilíbrios regionais, criando desníveis muito acentuados nas possibilidades de cada unidade federativa para a realização de planos educacionais, as áreas nas quais se reclama um esforço mais extenso são, precisamente, as que dispõem de menos recursos próprios para tal finalidade.

Orientando-se pela compreensão desses aspectos essenciais do problema educacional brasileiro, o Governo empenha-se em proceder, nessa área, a uma das mais profundas reformas de base, a fim de que os benefícios da educação deixem de constituir privilégio de grupos sociais e mesmo de regiões do próprio País.

Esforçar-se-á o Governo por assegurar a todos o direito à escola média, tornando-a acessível, em etapas sucessivas de escolarização, a toda a juventude, como ainda tentará recuperar a população que a falta secular de escolas tornou marginal do processo educacional e, por conseq ência, do sistema de produção. Por outro lado, imprimirá novo sentido ao sistema escolar, de modo que ele não sirva, apenas, a uma camada privilegiada, mas seja a forma de habilitação do homem comum para o trabalho e para a sua integração na comunidade nacional.

Democratização da cultura e habilitação profissional são os princípios básicos que nortearão todo o esforço governamental para que o sistema escolar possa satisfazer, de fato, as aspirações e necessidades do povo brasileiro. 


\section{Trabalhonecessário}

Issn: 1808 - 799X

ano 12, no $18-2014$

\section{ducação le en a e ul u a opula}

No campo do ensino elementar, a ação do Governo se fará sentir por meio dos recursos atribuídos pela nião aos Estados e aos Municípios, com o objetivo de proporcionar oportunidade de educação primária a todas as crianças da faixa etária de a 11 anos, das quais contamos ainda cerca de 6 milhões fora da escola. Constituem evidência as dificuldades que o País enfrenta para o alcance desse objetivo que, pelas razões mais diversas e complexas, demanda grande concentração de recursos para ser atingido em breve lapso de tempo. Entretanto, a ação planejada do Governo federal, somando-se aos esforços desenvolvidos pelos governos estaduais e municipais, permitirá que nos aproximemos decididamente do objetivo de escolarização de todas as crianças brasileiras compreendidas na faixa de educação compulsória.

Ao lado dessa meta quantitativa, o Governo continuará empenhando-se na realização de metas qualitativas, visando ao aperfeiçoamento do ensino elementar, notadamente em zonas rurais e até urbanas em que a escolarização primária se realiza nas mais precárias condições.

Assim sendo, definidos bem claramente, não apenas os objetivos do Governo, mas também a forma de sua atuação junto, aos Estados e Municípios, de acordo com as normas do planejamento educacional, deveremos prosseguir na execução do programa de construção de 5.984 salas e reequipamento de 10.000. Por meio dessas e de outras medidas objetivas e realistas que estão sendo postas em prática, espera o Governo, no decurso do presente ano, promover em todo o País um aumento superior a milhões no numera de vagas em nossa rede escolar de primeiro grau.

Por outro lado, atenção especial será dispensada à formação, aperfeiçoamento e especialização de professores primários - condição indispensável para a realização de todos os objetivos quantitativos e qualitativos que nos propomos no campo da educação elementar —, de tal forma que o Instituto Nacional de Estudos Pedagógicos deverá, em 1964, preparar .000 


\section{Trabalhonecessário}

Issn: 1808 - 799X

ano 12, no $18-2014$

professores-supervisores e especialistas em educação elementar e o Departamento Nacional de Educação, mais 1.150 professores-supervisores. Pretende ainda o Governo, no ano de 1964, promover ampla mobilização para alfabetizar mais de 5 milhões de brasileiros que vivem marginalizados por não possuírem o mínimo de condições culturais para participar do sistema de produção e do processo político que, cada vez mais, exigem cidadãos capazes de velar pelos interesses da comunidade. Nessa mobilização dever-se-á desenvolver ação cuidadosamente planejada, para que sejam utilizadas técnicas modernas e meios suficientes, aptos não apenas, a levar o analfabeto ao domínio do mecanismo da leitura e da escrita, mas também a habilitá-lo a participar conscientemente da vida política.

Procurar-se-á convocar para essa obra milhões de brasileiros, todos os setores da comunidade nacional que possam oferecer uma contribuição válida, tais como estudantes de ensino médio e superior, professores de todos os graus de ensino, escolas oficiais . e particulares, as classes produtoras e as orças Armadas. Não serão esquecidos os modernos recursos de comunicação, utilizando-se o sistema nacional de T -Rádio Educação e ainda 35 mil projetores, nos círculos de cultura - unidades alfabetizadoras que, no Sistema Paulo reire, substituem as clássicas e custosas salas de aula. Além disso, será assegurado todo o apoio do Governo aos movimentos e campanhas de cultura popular, partam de fontes oficiais ou sejam fruto de iniciativas particulares.

Por outro lado, dando cumprimento ao dispositivo constitucional do art. 168, item III, que estabelece a obrigatoriedade, por parte das empresas industriais, comerciais e agrícolas em que trabalhem mais de cem pessoas, de manutenção do ensino primário, gratuito para seus empregados e os filhos destes, o Governo baixou o Decreto no 53.453, que estabelece normas para a execução daquele preceito.

Outro problema que será enfrentado com o máximo de decisão é o dos salários do professorado primário brasileiro, infelizmente um dos mais baixos do mundo. Já foram adotadas as necessárias medidas, devendo a nião despender, 


\section{Trabalhonecessário}

Issn: 1808 - 799X

ano 12, no $18-2014$

no ano em curso, 10 bilhões de cruzeiros para a suplementação dos salários de 120 mil professores .

Atribuirá o Governo à educação elementar, tanto de crianças como de adultos, a maior soma de recursos e a mais absoluta prioridade de tratamento, uma vez que nesse nível se cruzam e encontram os dois grandes objetivos que devem presidir a todos os investimentos governamentais em matéria de educação: a democratização da cultura e o incremento da produção nacional.

\section{ducação dia}

No que diz respeito à educação de nível médio - grau escolar que está passando a constituir, cada vez mais, aspiração popular em todos os pontos do País, - o esforço do Governo será orientado no sentido de serem multiplicadas as oportunidades de educação sistemática para os 1 milhões de adolescentes brasileiros que, por motivos os mais diversos, não têm acesso às escolas de segundo grau, $\mathrm{Na}$ verdade, se considerarmos que esses 1 milhões representam nada menos de $90 \%$ da população compreendida na faixa etária de 11 a 16 anos, teremos de ceder à evidência de que há urgente necessidade de uma reformulação da política educacional do País, para adoção de planos mais realistas e até de emergência, capazes de impedir que essa aspiração popular continue frustrada, com grandes prejuízos para o desenvolvimento do País.

Ao lado disso, deverá o ano de 1964 ser decisivo para a nova orientação da nossa escola média, que se tornará mais adequada à realidade brasileira. Se é verdade que mais de 80 dos estudantes brasileiros de nível médio freq entam cursos secundários de orientação ainda teórica e formal, temos que imprimir à escola secundária sentido novo, levando-a a preparar para as atividades produtivas do País os 93 de matrículas que não se destinam a estudos universitários, mas às atividades industriais ou agrícolas e aos serviços em geral.

Em face, portanto, dessas duas necessidades - ampliação da rede escolar de grau médio e orientação do sistema no sentido da educação para o 


\section{Trabalhonecessário}

Issn: 1808 - 799X

ano 12, no $18-2014$

trabalho - elaborou o Governo extenso programa, todo ele já em expressivo ritmo de execução. Pretende-se, inicialmente, estender a todos os municípios brasileiros dos quais apenas 5 possuem ginásios ou colégios, a possibilidade de instalação de escolas de 20 grau. Para tanto, será incentivado o aproveitamento da capacidade ociosa dos grupos escolares a fim de que neles funcionem a $1^{\mathrm{a}} \mathrm{e}$ a $2^{\mathbf{a}}$ séries do primeiro ciclo, enquanto, nas cidades mais populosas, se cuidará de estender a escolaridade até à $3^{\mathrm{a}}$ e à $4^{\mathrm{a}}$ séries, possibilitando, progressivamente, a toda a população o acesso à escola média completa, principalmente em sua forma profissional, no $2^{\circ}$ ciclo, onde se preparam os técnicos de nível médio, condição indispensável a qualquer plano de desenvolvimento. $O$ Governo incentivará a mocidade a procurar o acesso à

niversidade por intermédio das escolas profissionais de 2 o ciclo, de modo que com um só investimento se atinjam os dois objetivos.

Continuar-se-á a construção de novas unidades escolares com os recursos atribuídos aos Estados e, ao mesmo tempo, executar-se-á um programa de recuperação da rede nacional de Escolas Técnicas, para onde será encaminhada, preferencialmente, a juventude, com o fito de melhor aproveitar a capacidade desses estabelecimentos e de torná-los aptos a ministrar: 1) cursos especiais vespertinos e noturnos de habilitação profissional para o pessoal qualificado das ind strias;

) cursos tecnológicos de formação profissional altamente qualificada para jovens graduados em nível colegial;

3) cursos especiais de formação profissional para jovens que freq entam ou freq entaram cursos ginasiais.

Para complementação dessas medidas de caráter quantitativo, prosseguirá o Governo o trabalho de emergência de preparação de professores para as séries iniciais do primeiro ciclo, por meio de cursos intensivos, pretendendo, dessa forma, atingir 0.000 docentes em 1964, enquanto se apresta para a solução ideal de formar em faculdades de filosofia todos os professores de ensino médio do País. 


\section{Trabalhonecessário}

Issn: 1808 - $799 X$

ano $12, n^{\circ} 18-2014$

A fim de atender à necessidade de reorientação de nossa escola de grau médio, grande esforço será concentrado na implantação da rede nacional de ginásios modernos", com a construção de 10 estabelecimentos desse gênero. Neles serão ministrados cursos de 2, 3 e 4 séries do 1ํ ciclo do nível médio, orientados no sentido da educação para o trabalho, por intermédio de ensino básico comum com opção pela prática de comércio, ind stria e agricultura, adaptado às condições locais, e da adoção, pelos ginásios já existentes, de um novo espírito de educação, voltado para a relação entre a escola, a família e a comunidade, para os problemas regionais e nacionais, e os do desenvolvimento, enfim, para a realidade a que deve estar vinculado o processo educativo.

Como essas medidas exigem decidida cooperação dos educadores, das famílias e dos próprios estudantes, a mais viva atenção será atribuída ao desenvolvimento dos programas, já iniciados, de ação junto a professores, pais e alunos, especialmente aqueles que se referem ao aperfeiçoamento de pessoal docente, técnico e administrativo: incentivo a experiências pedagógicas e sua difusão; (divulgação de oportunidades educacionais e orientação vocacional: assistência e orientação às associações de pais e mestres e aos círculos de pais; instalação de centros de documentação pedagógica; criação de escolas de mecanografia para estudantes de nível médio; assistência às organizações de estudantes e às entidades de classe dos educadores, além de numerosos outros projetos em pleno andamento, todos eles destinados à atualização, ao aperfeiçoamento e à expansão do ensino médio.

Empenha-se o Governo, presentemente, em vasta campanha de recuperação cultural de jovens de mais de 16 anos, visando a oferecer àqueles que nunca tiveram oportunidade de freq entar ginásios e colégios escolarização média por meio do Sistema Nacional de T -Rádio Educação, com o objetivo imediato de preparar meio milhão de jovens para os exames de madureza.

Com a mesma finalidade, regulamentou, pelo Decreto $\mathrm{n}-51.680-\mathrm{A}$, a realização dos exames de madureza e instituiu bancas permanentes para sua realização. 


\section{Trabalhonecessário}

Issn: 1808 - 799X

ano 12, no $18-2014$

Ao lado da expansão das escolas profissionais, vasto programa intensivo de habilitação profissional será desenvolvido para formar em 20 meses cerca de 50.000 trabalhadores qualificados nos mais diversos tipos de atividades.

Merece menção especial a providência de mandar matricular, em 1964, todos os alunos excedentes que, embora aprovados nos exames de admissão à $1^{\text {a }}$ série ginasial, não tenham alcançado o limite de vagas do estabelecimento. Para esse fim serão criadas novas classes e concedidas bolsas de estudo. Dessa forma, pretende o Governo impedir que qualquer aluno habilitado deixe de estudar por falta de vaga.

Os candidatos reprovados nos mesmos exames serão matriculados $6^{\mathbf{a}}$ série primária onde serão submetidos a regime de aprendizagem intensiva, que compreenderá a revisão do programa da $5^{\mathbf{a}}$ série e o ensino das disciplinas da $1^{\mathbf{a}}$ série ginasial. Os alunos sob esse regime prestarão exames para acesso à $2^{\mathbf{a}}$ série ginasial em 1965 e, por conseguinte, não perderão o ano, Essa providência, adotada pela primeira vez, atingirá cerca de 100 mil jovens que, impedidos de ingressar na escola secundária, quase sempre desistem dos estudos e se dirigem para em pregos para os quais não têm ainda preparação, passando, provavelmente, a engrossar a legião dos desajustados.

\section{í el upe io}

No ano de 1963, n mero pouco superior a 100 mil jovens conseguiu matricular-se em nossas universidades, e a grande maioria, em cursos de formação livresca. Isso significa que apenas $1 \%$ de nossa juventude tem acesso aos estudos de nível superior.

Pelo visto, como o ensino de grau médio, também o superior está longe de atender à necessidade de técnicos para o desenvolvimento industrial.

Para corrigir essa grave deficiência, o dispendioso sistema de ensino superior do País participará do esforço do Governo para formação de mão-de-obra de urgência, mediante a reformulação dos programas universitários e pela 


\section{Trabalhonecessário}

Issn: 1808 - 799X

ano 12 , no $18-2014$

duplicação de matrículas no primeiro ano dos cursos universitários, determinada no Decreto no 53.642, de 28 de fevereiro de 1964.

Assim, será estabelecida conexão entre as universidades e o sistema de produção para que o investimento feito na rede de ensino superior tenha imediata rentabilidade, neste momento crucial de reforma de estruturas e conseq ente aumento da procura de técnicos. Por outro lado, toda capacidade ociosa das instalações e do pessoal de nível universitário será usada para habilitação profissional de nível médio, para campanhas de cultura popular e difusão de conhecimentos básicos entre o povo, de modo que seja ressarcido, em proveito do povo, o pesado ônus que representa para o País a manutenção desse caríssimo sistema escolar.

Para esse efeito, a niversidade ederal de São Paulo, localizada no A C paulista, zona de grande concentração industrial, tomou a iniciativa de instalar cursos de formação de técnicos de alto nível, engenheiros de grau médio, que assistirão às aulas teóricas na própria niversidade, e às práticas, nas principais ind strias da região.

Com a finalidade de melhorar o nível dos candidatos às escolas superiores, estão sendo criados Colégios niversitários junto às niversidades ederais e às

Católicas, num total de

niversidade do Ceará e na

capacidade para receber ciclo secundário.

Ainda neste capítulo de autêntica reforma universitária empreendida pelo Governo, para atender às exigências do nosso desenvolvimento, inserem-se as medidas para corrigir a estrutura fragmentária, que multiplica, dentro da mesma Universidade, instalações, equipamentos e pessoal para tarefas idênticas, provocando a desproporção entre os seus orçamentos e o $\mathrm{n}$ mero de alunos matriculados e, por conseguinte, determinando baixa rentabilidade do investimento $\mathrm{p}$ blico. 


\section{Trabalhonecessário}

Issn: 1808 - 799X

ano 12 , no $18-2014$

A centralização do ensino e da pesquisa em grandes setores básicos, a serviço de toda a niversidade, com eliminação dos $\mathrm{n}$ cleos dispersos pelas suas várias unidades, representará substancial economia de meios, por um lado, c, por outro, a possibilidade de ampliar as matrículas nas escolas, seja no ciclo básico, seja no ciclo profissional.

Sem qualquer lesão da autonomia universitária, o Ministério da Educação e Cultura exercerá a ação estimuladora e supletiva que lhe cabe, cooperando com a universidade na criação desses setores básicos ou na consolidação dos que, de modo mais ou menos desenvolvido, já existem em algumas delas.

Obedecendo a esse critério, a niversidade ederal de São Paulo criou os Institutos ásicos de uímica, ísica, iologia, Matemática, estando em estudos a instalação de um Instituto de ioquímica. Com a criação de tais institutos, propicia-se, de imediato, a absorção de todos os excedentes dos exames vestibulares, isto é, de candidatos que, embora aprovados, não tenham obtido vaga nas escolas da atual estrutura universitária.

Esta política universitária estender-se-á a todas as universidades federais que a nião mantém.

\section{ni e idade de a ília}

Enquanto se cuida de democratizar o sistema escolar de todos os níveis e de colocá-lo a serviço do esforço nacional para o desenvolvimento, no Distrito ederal, por intermédio do Projeto Piloto da niversidade de rasília, implanta-se novo modelo de universidade, semelhante às mais avançadas organizações internacionais. A niversidade de rasília destina-se, sobretudo, a assessorar tecnicamente o Governo brasileiro e tem por objetivos a formação científica de alto nível e o estudo dos problemas nacionais, no propósito de contribuir para a formação de soluções compatíveis com a realidade do País. Em todos os Estados estão sendo recrutados aqueles que desejam dedicar-se à cultura e à pesquisa, de modo que essa niversidade já começa a constituir-se em $n$ cleo de uma 


\section{Trabalhonecessário}

Issn: 1808 - 799X

ano 12 , no $18-2014$

autêntica elite intelectual empenhada no estudo e na solução dos $\mathrm{m}$ Itiplos problemas nacionais no campo da cultura.

\section{o ça ada}

Sendo a educação investimento caríssimo, constituindo, talvez, o mais pesado ônus impostos à comunidade, o esforço governa- mental nessa área se apoiará nas forças vivas da nação, para ele convocando-se todas as disponibilidade nacionais. Dos profissionais e das classes produtoras aos estudantes e às orças Armadas, serão todos convocados para o grande esforço de eliminação do subdesenvolvimento por intermédio da difusão cultural. Principalmente as orças Armadas, que têm participado, como elemento de vanguarda, de todos os movimentos históricos, serão convocadas para essa batalha pela integração na vida nacional das populações que ficaram à margem do processo histórico do País.

Em 1963, o Exército colaborou eficazmente neste importante setor de atividade, quer por meio do grande $n$ mero de escolas de alfabetização existentes em todas as unidades, quer por intermédio da rede de escolas de ensino médio e superior sob a sua responsabilidade.

A propósito, convém salientar que, em lugares quase inacessíveis ao homem civilizado, onde exista contingente militar, embora de reduzido efetivo, como acontece nas fronteiras da Amazônia e Mato Grosso, sempre se instala uma escola e dela sai alfabetizado grande $n$ mero de crianças, que muitas vezes ignoravam até mesmo o idioma nacional. Assim, as orças Armadas têm colaborado com o Ministério da Educação e Cultura no programa de instalação das Escolas de ronteira. Esse aprendizado rudimentar, porém til, foi crescendo de eficiência à proporção que as unidades se aproximavam dos grandes centros, culminando na Vila Militar da Guanabara com o ensino ministrado pela televisão a centenas de soldados.

Os professores são, em princípio, oficiais e graduados. 


\section{Trabalhonecessário}

Issn: 1808 - 799X

ano 12, no $18-2014$

Nos cursos de grau médio e nos de grau superior, os resultados foram promissores, uma vez que 1.269 alunos os concluíram, com alto grau de aproveitamento.

Saliente-se que a continuação em funcionamento dos Colégios Militares de Curitiba, elo orizonte, Salvador e Recife veio ao encontro das justas aspirações da numerosa classe militar, cujos encargos com a educação dos seus dependentes se tornam cada vez mais onerosos.

Continuará em funcionamento, graças ao Decreto no 5 .948, de 6-11-63, a Escola Preparatória de Campinas, cuja extinção estava prevista para 31 de dezembro Itimo.

O Instituto Militar de Engenharia formou 77 engenheiros, ao passo que concluíram o curso da Escola de Comando e Estado-Maior, 5 oficiais; no da Escola Superior de Guerra foram matriculados pelo Exército: Generais, 13 Coronéis e 4 Tenentes- Coronéis (Curso Superior); 3 Coronéis, 11 Tenentes-

Coronéis (CEMCFA).

$\mathrm{Na}$ Marinha, a especialização de oficiais e de praças é feita em cursos correspondentes às 6 especializações de oficiais do Corpo da Armada e às 6 especialidades de marinheiros e taifeiros. Alguns dos cursos de especialização para oficiais e praças do Corpo de uzileiros Navais continuaram a ser feitos em escolas do Exército, que nesse setor presta inestimável colaboração à Marinha.

Também prosseguiram a formação de engenheiros, mediante convênio mantido com a niversidade de São Paulo, e a realização de cursos pós-graduação para médicos e dentistas em escolas civis.

A Escola de Guerra Naval preencheu as suas funções de centro de estudos de alto nível e de escola de estado-maior, ministrando, entre outros, cursos a oficiais superiores de nações amigas. O Ministério da Aeronáutica mantém diversos estabelecimentos de formação e de aperfeiçoamento de pessoal e formou 559 especialistas de vários níveis, em 1963. oi ampliada a formação de sargentos especialistas na Escola de Especialistas 


\section{Trabalhonecessário}

Issn: 1808 - 799X

ano $12, n^{\circ} 18-2014$

de Guaratinguetá, assim como a formação de oficiais especialistas na Escola de Oficiais Especialistas, em Curitiba.

O Instituto Técnico de Aeronáutica que é, hoje, uma escola-padrão no seu gênero, continuou, em 1963, a formar especialistas, muitos deles destinados à ind stria civil. Parcela já significativa de mão-de-obra altamente qualificada absorvida pela aviação comercial e pela ind stria automobilística e de motores vem sendo formada no I. T. A. que, assim, desempenha papel dos mais relevantes como centro de instrução técnico-profíssional.

A formação de técnicos torna-se, cada vez mais, o fator crítico no desenvolvimento de uma orça Aérea moderna. De nada servirá o material avançado se não se contar com técnicos de qualidade altamente especializados, necessários à sua utilização. Impõe-se mesmo um estudo profundo e a obtenção, junto ao Congresso, de leis que permitam a justa remuneração de técnicos de alta qualidade, se desejarmos desenvolver a orça Aérea rasileira de acordo com os padrões de adiantamento e eficiência que a atualidade está a exigir" (p. 159-174).

\section{A Primeira Lei sobre Educação sancionada pelo Presidente Castelo Branco}

Lei no 4.464, de 9 de Novembro de 1964

(Substituída pelo Decreto-lei no 228/1967 e, posteriormente pelo Decreto-Lei oㅡ 477/1969, pela Lei ํo 6.680/1979 e pela Lei oำ7.395/85).

Dispõe sobre os Órgãos de Representação dos estudantes e dá outras providências. O PRESIDENTE DA REPÚBLICA, faço saber que o CONGRESSO NACIONAL decreta e eu sanciono a seguinte lei:

Art. $1^{\circ}$ Os órgãos de representação dos estudantes de ensino superior, que se regerão por esta Lei, têm por finalidade:

a) defender os interesses dos estudantes;

b) promover a aproximação e a solidariedade entre os corpos discente, docente e administrativo dos estabelecimentos de ensino superior; 


\section{Trabalhonecessário}

Issn: 1808 - $799 X$

ano $12, \mathrm{n}=18-2014$

c) preservar as tradições estudantis, a probidade da vida escolar, o patrimônio moral e material das instituições de ensino superior e a harmonia entre os diversos organismos da estrutura escolar;

d) organizar reuniões e certames de caráter cívico, social, cultural, científico, técnico, artístico, e desportivo, visando à complementação e ao aprimoramento da formação universitária;

e) manter serviços de assistência aos estudantes carentes de recursos;

f) realizar intercâmbio e colaboração com entidades carentes de recursos;

g) lutar pelo aprimoramento das instituições democráticas.

Art. $2^{\circ}$ São órgãos de representação dos estudantes de ensino superior:

a) o Diretório Acadêmico (D.A.), em cada estabelecimento de ensino superior;

b) o Diretório Central de Estudantes (D.C.E.), em cada Universidade;

c) o Diretório Estadual de Estudantes (D.E.E.), em cada capital de Estado, Território ou

Distrito Federal, onde houver mais de um estabelecimento de ensino superior;

d) o Diretório Nacional de Estudantes (D.N.E.), com sede na Capital Federal.

Parágrafo único - VETADO.

Art. 3․ Compete, privativamente, ao Diretório Acadêmico e ao Diretório Central de Estudantes, perante as respectivas autoridades de ensino da Escola, da Faculdade e da Universidade:

a) patrocinar os interesses do corpo docente;

b) designar a representação prevista em lei junto aos órgãos de deliberação coletiva e bem assim junto a cada Departamento constitutivo de Faculdade, Escola ou Instituto integrante de Universidade;

$\S 1^{\circ}$. A representação a que se refere a alínea b deste artigo será exercida, junto a cada órgão, por estudante ou estudantes regularmente matriculados, em série que não a primeira, sendo que, no caso de representação junto a Departamento ou Instituto deverá ainda recair em aluno ou alunos de cursos ou disciplinas que o integrem, tudo de acordo com regimentos internos das Faculdades, Escolas e estatutos das Universidades.

$\S 2^{\circ}$. A representação estudantil junto ao Conselho Universitário, Congregação ou Conselho-Departamental poderá fazer-se acompanhar de um aluno, sempre que se tratar de assunto do interesse de um determinado curso ou seção.

Art. 4ํㅡㄹ Compete ao Diretório Estadual de Estudantes realizar, com amplitude estadual, as finalidades previstas no art. $1^{\circ}$ desta Lei.

Art. 5ํำ Diretório Acadêmico será constituído por estudantes de ensino superior, eleitos pelo respectivo corpo discente.

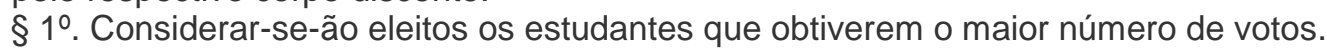

$\S 2^{\circ}$. A eleição do Diretório Acadêmico será feita pela votação dos estudantes regularmente matriculados.

$\S 3^{\circ}$. O exercício do voto é obrigatório. Ficará privado de prestar exame parcial ou final, imediatamente subseqüente à eleição, o aluno que não comprovar haver votado no referido pleito, salvo por motivo de doença ou de força maior, devidamente comprovado. $\S 4^{\circ}$. O mandato dos membros do Diretório Acadêmico será de um ano, vedada a reeleição para o mesmo cargo.

Art. 6ำ A eleição do Diretório Acadêmico será regulada em seu regimento, atendidas as seguintes normas:

a) registro prévio de candidatos ou chapas, sendo elegível apenas o estudante regularmente matriculado, não-repetente, ou dependente, nem em regime parcelado; 


\section{Trabalhonecessário}

Issn: 1808 - 799X

ano 12, no $18-2014$

b) realizado dentro do recinto da Faculdade, em um só dia, durante a totalidade do horário de atividades escolares;

c) identificação do votante mediante lista nominal fornecida pela Faculdade;

d) garantia de sigilo do voto e da inviolabilidade da urna;

e) apuração imediata, após o término da votação, asseguradas a exatidão dos resultados a possibilidade de apresentação de recurso;

f) acompanhamento por representante da Congregação ou do Conselho Departamental, na forma do regimento de cada Faculdade;

Parágrafo único. A mudança para regime parcelado, trancamento da matrícula ou conclusão de curso importa em cassação de mandato.

Art. 7ํㅡ Diretório Estadual de Estudantes será constituído de representantes de cada Diretório Acadêmico ou grupos de Diretórios Acadêmicos existentes no Estado, havendo um máximo de vinte representantes.

Art. 8 A eleição para o Diretório Central de Estudantes e para o Diretório Estadual de Estudantes será regulada nos respectivos regimentos, atendidas, no que couber, as normas previstas no art. 6ํㅡㄹ e seu parágrafo único.

Art. 9 A composição, organização e atribuições dos órgãos de representação Estudantil serão fixadas em seus regimentos, que deverão ser aprovados pelos órgãos a que se refere o artigo 15. Parágrafo único $\mathrm{O}$ exercício de quaisquer funções de representação, ou delas decorrentes, não exonera o estudante do cumprimento dos seus deveres escolares, inclusive da exigência de frequência.

Art. 10. O Diretório Nacional de Estudantes, órgão coordenador das atividades dos Diretórios Estudantis, que cuidará da aproximação entre os estudantes e o Ministério da Educação e Cultura e que, no seu âmbito de ação, terá as obrigações e os direitos expressos no art. 1ํㅡㄴ observará todos os preconceitos gerais desta Lei.

§ 1 Poderá ainda o Diretório Nacional de Estudantes promover, durante os períodos de férias escolares, reuniões de estudantes, para debates de caráter técnico.

$\S 2^{\circ} \mathrm{O}$ Diretório Federal em que haja órgão previsto no art. $2^{\circ}$, sendo a sua primeira constituição feita dentro do prazo de noventa dias, mediante eleições procedidas nos Diretórios Estaduais e instruções do Ministério da Educação e Cultura, que fará a primeira convocação.

$\S 3^{\circ}$ O Diretório Nacional de Estudantes se reunirá na Capital Federal durante os períodos de férias escolares, dentro dos prazos e condições estabelecidos no regimento, podendo reunir-se extraordinariamente, em qualquer época, por iniciativa justificada da maioria absoluta dos seus membros, do Ministério da Educação e Cultura, ou do

Conselho Federal de Educação, em local previamente designado.

Art. 11. Aplicam-se ao Diretório Estadual de Estudantes, ao Diretório Central de Estudantes e ao Diretório Nacional de Estudantes as normas estabelecidas no art. 5ํ e seus parágrafos desta Lei.

Art. 12. As Faculdades e Universidades assegurarão os processos de reconhecimento das contribuições dos estudantes.

$\S 1$ 으 $\mathrm{O}$ regimento do Diretório Estadual de Estudantes poderá prever a perda dos mandatos de representantes de Diretórios Centrais e de Diretórios Acadêmicos, bem como o regimento do Diretório Central poderá estabelecer a perda de mandato dos 
Issn: 1808 - 799X

ano 12, no $18-2014$

representantes dos Diretórios Acadêmicos, quando os órgãos representados não efetuarem regulamente o pagamento das contribuições que lhe competem.

$\S 2^{\circ}$ Os órgãos de representação estudantil são obrigados a lançar todo o movimento de receita e despesa em livros apropriados, com a devida comprovação.

$\S$ 3ํㅡㄴ Os órgãos de representação estudantil apresentarão prestação de contas, ao término de cada gestão, aos órgãos a que se refere o artigo 15 , sendo que a nãoaprovação das mesmas, se comprovado o uso internacional e indevido dos bens e recursos da entidade, importará em responsabilidade civil, penal e disciplinar dos membros da Diretoria.

Art. 13. Os auxílios serão entregues às Universidades, Faculdades ou Escolas isoladas que darão a destinação conveniente e encaminharão os processos de prestação de contas, acompanhadas de parecer.

Art. 14. É vedada aos órgãos de representação estudantil qualquer ação, manifestação ou propaganda de caráter político-partidário, bem como incitar, promover ou apoiar ausências coletivas aos trabalhos escolares.

Art. 15. A fiscalização do cumprimento desta Lei caberá à congregação ou ao Conselho Departamental na forma de regimento de cada Faculdade ou Escola, quanto ao Diretório Acadêmico; ao Conselho Universitário, quanto ao Diretório Central de Estudantes, e ao Conselho Federal de Educação, quanto ao Diretório Estadual de Estudantes e ao Diretório Nacional de Estudantes.

Parágrafo único. O Conselho de Educação poderá delegar poderes de fiscalização aos Conselhos Universitários.

Art. 16. O regimento de cada Faculdade ou escola e estatuto de cada Universidade disporão sobre o prazo dentro do qual seus órgãos deliberativos deverão pronunciar-se sobre as representações feitas pelos órgãos de representação estudantil.

Parágrafo único. Quando a matéria for relativa ao previsto no $\S 2^{\circ}$ do artigo 73 , Lei de Diretrizes e Bases da Educação Nacional, a decisão de Faculdade ou Escola deverá ocorrer:

a) no prazo de dez dias, em se tratando de não-comparecimento do professor, sem justificação, a $25 \%$ das aulas e exercícios;

b) antes do início do ano letivo seguinte, no caso de não comparecimento de, pelo menos, três, quartos do programa da respectiva cadeira.

Art. 17. O Diretor de Faculdade ou Escola e o Reitor de Universidade incorrerão em falta grave se por atos, omissão ou tolerância, permitirem ou favorecerem o não cumprimento desta Lei.

Parágrafo único. Às Congregações e aos Conselhos Universitários caberá a apuração da responsabilidade, nos termos deste artigo, dos atos que forem levados a seu conhecimento.

Art. 18. Poderão ser constituídas fundações ou entidades civis de personalidade jurídica para o fim específico de manutenção de obras de caráter assistencial, esportivo ou cultural de interesse dos estudantes.

Parágrafo único. Nos estabelecimentos de ensino de grau médio, somente poderão constituir-se grêmios com finalidades cívicas, culturais, sociais e desportivas, cuja atividade se restringirá aos limites estabelecidos no regimento escolar, devendo ser sempre assistida por um professor. 


\section{Trabalhonecessário}

Issn: 1808 - 799X

ano 12, no $18-2014$

Art. 19. As Universidades e os estabelecimentos de ensino superior adaptarão seus estatutos aos termos da presente Lei, no prazo improrrogável de sessenta (60) dias.

Art. 20. Os atuais órgãos de representação estudantil deverão proceder à reforma de seus regimentos, adaptando-os à presente Lei e os submetendo às autoridades previstas no art. 15, no prazo improrrogável de sessenta (60) dias.

Art. 21. Os casos omissos nesta Lei serão resolvidos pelo Conselho Federal de Educação.

Art. 22. Esta Lei entrará em vigor na data de sua publicação, ficando revogados o Decreto-Lei no 4.105 , de 11 de fevereiro de 1942, e as demais disposições em contrário.

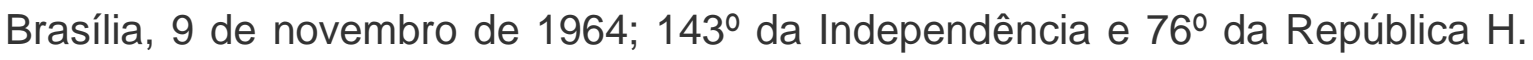
CASTELLO BRANCO Flávio [Suplicy de] Lacerda.

Este texto não substitui o original publicado no Diário Oficial da União Seção 1 de 11/11/1964.

\section{Considerações finais}

Ao trazer estes documentos à memória de nossos leitores, de nenhuma forma podemos afastar as análises realizadas em um número significativo de textos, dentre os quais exemplarmente referenciamos o de Germano (1993) e o de Cunha \& Góes (1996). A intenção primeira é a de oferecer, na materialidade documental, a oportunidade de se constatar o estancamento dos movimentos da sociedade em busca de soluções para seus desafios. Pela arbitrária imposição da vontade de um grupo, com o uso da força, anulam-se as possibilidades de discussão com os demais grupos. Por isso, a primeira ação da ditadura de 1964 é a do "aperfeiçoamento" dos mecanismos de controle e dissuasão.

Mas a intenção segunda, e nem por isso menos principal, é a de resgatar as propostas amadurecidas na sociedade e sistematizadas na Mensagem do Presidente João Goulart ao Congresso Nacional. Havia uma proposta apontando para um debate e uma institucionalização a ser democraticamente construída no Parlamento e na sociedade brasileira. A força armada impôs suas preferências 


\section{Trabalhonecessário}

Issn: 1808 - 799X

ano 12, no $18-2014$

pelos atos ditatoriais. Sonegar a discussão, o processo de construção pela sociedade, coibir o movimento de docentes e discentes, este foi o primeiro "golpe na educação". 


\section{Trabalhonecessário}

Issn: 1808 - $799 X$

ano 12 , no $18-2014$

\section{Referências}

BRASIL. PRESIDÊNCIA DA REPÚBLICA. Discurso do Presidente João Goulart no comício de 13 de março de 1964 na Central do Brasil, Rio de Janeiro. Disponível em http://www.institutojoaogoulart.org.br/conteudo.php?id=31. Acesso em maio de 2014.

BRASIL. PRESIDÊNCIA DA REPÚBLICA. Mensagem ao Congresso Nacional remetida pelo Presidente da República [João Goulart] na abertura da Sessão Legislativa de 1964. Disponível em http://www.biblioteca.presidencia.gov.br/expresidentes/joao-goulart/mensagens-presidenciais/mensagem-ao-congressonacional-na-abertura-na-sessao-legislativa-de-1964/view . Acesso em maio de 2014.

BRASIL. PRESIDÊNCIA DA REPÚBLICA. Discurso do Presidente Humberto de Alencar Castelo Branco na Universidade Federal do Ceará, em 23 de junho de 1964. Disponível em http://www.biblioteca.presidencia.gov.br/expresidentes/castello-branco/discursos-1/1964/30.pdf/view . Acesso em maio de 2014.

BRASIL. Decreto-Lei no 228, de 28 de fevereiro de 1967. Disponível em http://www.planalto.gov.br/ccivil 03/decreto-lei/Del0228.htm. Acesso em maio de 2014.

BRASIL. Decreto-Lei no 477, de 26 de fevereiro de 1969. Disponível em http://www.planalto.gov.br/ccivil 03/decreto-lei/1965-1988/Del0477.htm. Acesso em maio de 2014.

BRASIL. Lei no 4.464, de 9 de novembro de 1964. Disponível em http://www.planalto.gov.br/ccivil 03/leis/1950-1969/L4464.htm. Acesso em maio de 2014.

BRASIL. Lei no 6.680, de 16 de agosto de 1979. Disponível em http://www.planalto.gov.br/ccivil 03/LEIS/1970-1979/L6680.htm\#art5. Acesso em maio de 2014.

BRASIL. Lei no 7.395, de 31 de outubro de 1985. Disponível em http://www.planalto.gov.br/ccivil 03/LEIS/L7395.htm\#art7. Acesso em maio de 2014.

CUNHA, Luiz Antônio. GÓES, Moacyr de. O Golpe na Educação. Rio de Janeiro: Editora Jorge Zahar, 1996.

GERMANO, José Willigton. Estado Militar e Educação no Brasil (1964 - 1985). São Paulo/Campinas: Cortez/UNICAMP, 1993. 